\title{
Californian labs feel the heat of energy crisis
}

Rex Dalton, San Diego

Power-hungry research laboratories in California face their first blackouts this summer, after the withdrawal of exemptions that protected their electricity supplies.

Laboratories operating for the Department of Energy and NASA have been told that their power may be shut off for up to two hours at a time. Most electricity users in the state have faced similar cuts this month as warmer weather has increased the use of air conditioning. The blackouts are expected to become more frequent over the summer.

California has faced growing electricity shortages after a botched attempt to deregulate the state's electricity industry.

The Lawrence Berkeley laboratory and the Stanford Linear Accelerator Center (SLAC) have been told to expect notices from the California Public Utilities Commission (PUC) saying they will no longer be exempt.

The power cuts are likely to play havoc with long-planned experimental schedules. Cuts without warning may damage expensive equipment and could even endanger staff, say officials, who are appealing to the state to restore their exempted status.

So far the PUC has not issued a decision. "It is a very chaotic situation," says particle physicist Pier Oddone, deputy director of the Lawrence Berkeley laboratory, where the equipment likely to be affected includes the Advanced Light Source.

Officials at SLAC say that it has reduced its power use voluntarily, and that power cuts would wreck its main high-energy physics experiments because of the time they take to shut down and restart. "A blackout would be a total disaster," says acting deputy director Gregory Loew. "We are trying to figure a way to mitigate this."

The PUC has already sent warnings to NASA's Ames Research Center at Moffett Field, which operates energy-intensive wind tunnels, and to a test facility for high explosives operated by the Lawrence Livermore nuclear weapons laboratory. The main Livermore laboratory - like Berkeley and SLAC, a US Department of Energy (DOE) facility - is expected to stay exempt because of its nuclear weapons work, says DOE official Mark Clark. But officials fear that Livermore may face energy restrictions in the months ahead.

At the General Atomics fusion facility in San Diego, which has not been exempt from the power cuts, the experimental schedule has already been disrupted. The normal January-to-September schedule for operating the DIII-D tokamak device has been shortened to complete the necessary work by mid-June, after which the crisis is likely to worsen. The facility's electricity bill has jumped from $\$ 1$ million to $\$ 2.5$ million a year, prompting staff cuts and delays in purchases, says physicist Ronald Stambaugh, director of the DIII-D programme.

The other laboratories avoided the blackouts that swept California last winter because they held electricity contracts with another division of the DOE. But the PUC issued an order last month to change the rules governing such contracts. The new rules grant exemption only to users such as hospitals, and water and sewage facilities.
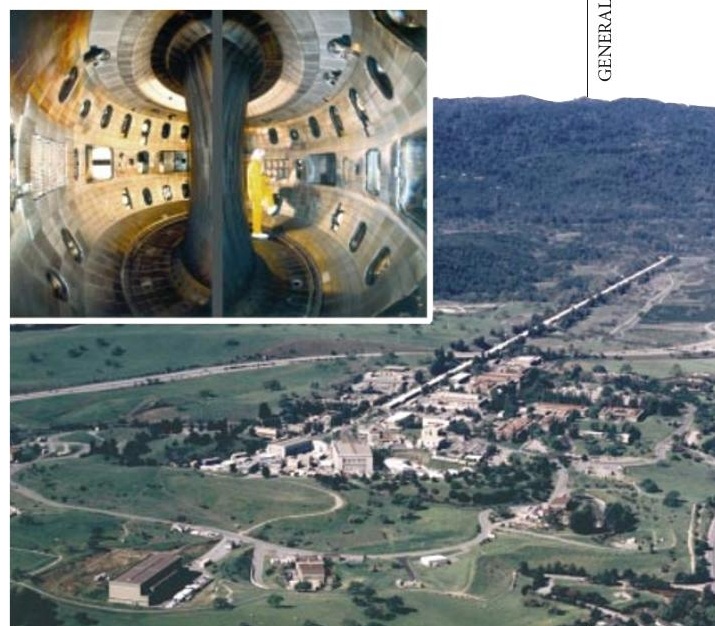

Cutting edge: the power shortage is already affecting the DIII-D tokamak (top) and SLAC.

\section{Angry researchers pour scorn on astrology classes}

\section{K. S. Jayaraman, New Delhi}

A proposal by the Indian government to encourage universities to teach astrology has sparked a storm of protest among scientists.

The University Grants Commission (UGC) has offered to fund fully fledged departments of astrology with five teaching posts, a library, computer laboratory and horoscope bank. To be called Jyotir Vigyan

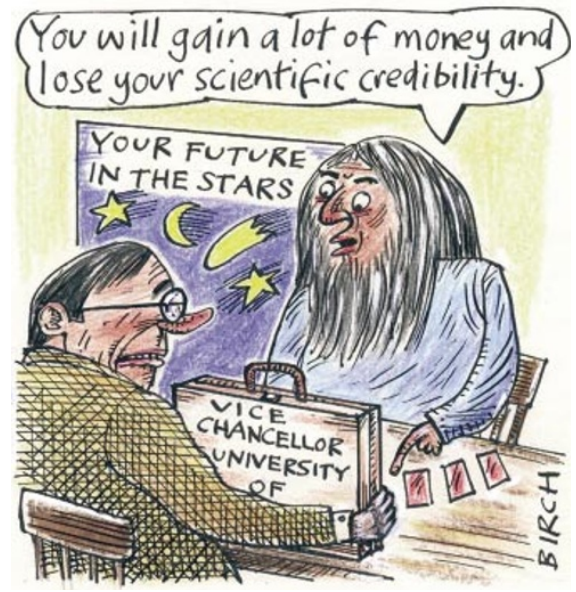

('astrological science' in Sanskrit), the departments are to be set up for the 2001-2002 academic year. They will offer bachelors, masters and doctoral degrees.

The proposal is the brainchild of science minister Murli Manohar Joshi, who is also minister for education and a powerful figure in the ruling Bharatiya Janata Party. Joshi, a physicist, believes that all answers sought by scientists are buried in the ancient Sanskrit writings called Vedas and Upanishads.

Leading researchers have condemned the move as an attempt to legitimize pseudoscience and superstition, and some have said that it undermines India's scientific credibility. The National Science Academy has expressed strong opposition. But there is no sign of the government relenting.

Meanwhile, 35 of India's roughly 200 universities have sought permission to set up courses, with more expected to follow.

"At a time when research in fields of pure science is being affected for want of funds, there is no justification in spending huge amounts on pseudoscience called Vedic astrology," said Pushpa Bhargava, founding director of the Centre for Cellular and Molecular Biology in Hyderabad.

Defending the move, UGC chairman Hari Gautam said that astrology qualifies as a science, which he defined as "a subject that needs probing, investigation and research".

Two prominent UGC members S. K. Joshi, a physicist and former director general of the Council of Scientific and Industrial Research, and Sipra GuhaMukherjee, a plant molecular biologist from Jawaharlal Nehru University in New Delhi - seem to have consented to the move. And some researchers, including Vijay Bhatkar, who developed India's first supercomputer, have publicly backed it.

"There is no doubt that the move is tantamount to giving [a] certain amount of formal recognition to astrology as a science," said Valangiman Ramamurthi, secretary to the Department of Science and Technology. "I do not want to comment whether it is right or wrong, but if anyone comes to me with a research proposal on astrology we will evaluate it to see if it makes sense scientifically before funding it." 